\title{
Poor Health-Related Quality of Life of Patients with Indication for Chronic Cardiac Pacemaker Therapy
}

\author{
J.W. MARTIJN VAN ECK, M.D., * NORBERT M. VAN HEMEL, M.D., PH.D.,† \\ JOHANNES. C. KELDER, M.D.,‡ ARJAN A. VAN DEN BOS, M.D., PH.D.,§ \\ WILLIAM TAKS, $\S$ DIEDERICK E. GROBBEE, M.D., PH.D., *
}

and KAREL G.M. MOONS, PH.D., * ON BEHALF OF THE FOLLOWPACE INVESTIGATORS

From the *Julius Center for Health Sciences and Primary Care, University Medical Center, Utrecht, The Netherlands, tDepartment of Cardiology, University Medical Centre, Utrecht, The Netherlands, ‡Department of Cardiology, St.

Antonius Hospital, Nieuwegein, The Netherlands, and §Department of Cardiology, Amphia Hospital, Breda,

The Netherlands

Background: Studies on health-related quality of life (HRQoL) of patients awaiting pacemaker (PM) implantation are scarce, or executed in specific patient subgroups (regarding age or specific cardiac rhythm disorders). The purpose of this study was to systematically assess the HRQoL in a large unselected cohort of patients with a conventional indication for PM therapy.

Methods: Pre-PM implantation HRQoL (measured with the SF-36 questionnaire, completed at hospital admission) of 818 consecutive Dutch patients included in the FOLLOWPACE study was compared with the HRQoL in a sample of the general Dutch population, and with several cohorts of patients with other conditions. Linear regression analysis was performed to analyze determinants of this HRQoL.

Results: Almost all SF-36 subscale scores were substantially and significantly lower in the PM patients compared to the general population, with P-values $<0.001$ in all SF-36 subscales except for "pain" and "general health perception." In the PM patients, presence of comorbidities, gender, and age were significantly associated with the overall physical component summary score (mean $38.8 \pm 27$ standard deviation) whereas the overall mental component summary score (46.8 \pm 27.0$)$ was associated with gender and age.

Conclusion: The HRQoL of patients before first PM implantation is significantly lower than that of a general population and also various other patient populations. Physicians should be aware of this unfavorable condition and keep the time interval between the diagnosis of a cardiac rhythm disorder requiring PM implantation and the implantation procedure as short as possible. (PACE 2008; 31:480-486)

pacemaker, rhythm disorders, quality of life, SF-36, comparison, determinants

\section{Introduction}

Since the early 1980s health-related quality of life (HRQoL) has evolved to a well-known validated and widely used tool to assess outcomes of medical therapies, including pacemaker (PM) therapy. ${ }^{1-6}$ Methods to summarize the answers or results of all these questionnaires and how to reflect their clinical relevance have also been reported..$^{2,5,7-11}$ The HRQoL of patients with cardiac rhythm disorders requiring the implantation of a PM or already having a PM has been reported

The study was funded by The Dutch College of Health Care (CVZ/VAZ grant number 01236) Netherlands Pacemaker Registry Foundation, Groningen, Jacques H. de Jong Foundation, Roger Crowson Foundation for Human Arrhythmias Studies, and all Dutch pacemaker distributors and manufacturers.

Address for reprints: J.W. Martijn van Eck, M.D. Julius Center for Health Sciences and Primary Care, Bolognalaan 12, 3584 CJ Utrecht, The Netherlands. Fax: 0031-30-2505481; e-mail: j.w.m.vaneck-2@umcutrecht.nl

Received November 14, 2007; revised January 8, 2008; accepted January 13, 2008. in previous studies. ${ }^{12-19}$ These studies, however, applied a nonvalidated questionnaire to measure HRQoL, were based on a small sample size, or most importantly studied a specific patient subgroup such as elderly patients or patients with specific cardiac rhythm disorders, ${ }^{12-15}$ whereas some studies only addressed the improvement of HRQoL after PM implantation. ${ }^{14-17,19}$ Furthermore, previous published data on factors influencing HRQoL of patients awaiting a first PM implantation are inconclusive and comparisons of this HRQoL with a general population and patient groups with various other diseases have never been published.

The purpose of this report of the Dutch multicenter prospective FOLLOWPACE study, which includes patients with conventional reasons for chronic pacing, ${ }^{20}$ was to assess determinants (such as patient's gender, age, Body Mass Index (BMI), cardiac history, and pacing indication) of HRQoL and to compare the baseline health perception (before PM implantation) in an unselected population of patients awaiting PM implantation with a general population and other patient cohorts. ${ }^{21}$

(C)2008, The Authors. Journal compilation (C)2008, Blackwell Publishing, Inc. 


\section{Methods}

\section{Patients}

This article describes the information retrieved from a cohort of 818 patients included between January 2004 and January 2007, in a multicenter prospective longitudinal cohort study, executed in 24 (of the 104) PM centers in The Netherlands, the FOLLOWPACE study. The design of the FOLLOWPACE study has been published previously. ${ }^{21}$ In brief, FOLLOWPACE was designed as a prospective cohort study to systematically document the PM implantation procedure as well as the routine follow-up in patients with cardiac rhythm disorders in The Netherlands. No specific recommendations on methods of therapy or follow-up were provided to the study centers. FOLLOWPACE was purely designed as an observational-not an interventional-study in an unselected population.

FOLLOWPACE included all consecutive patients (during the study period in the participating hospitals) aged 18 years and over, hospitalized for the implantation of a PM for conventional reasons, including atrioventricular conduction disturbances, sick sinus syndrome, bradytachycardias, and atrial fibrillation with a slow ventricular response. ${ }^{20}$ The purpose was to gather information of an unselected patient population leading to general applicability of the study results, and reflecting daily practice. Patients awaiting their first PM implantation in one of the 24 participating centers were potential candidates for this study. Patients were not eligible if they declined to participate or were participating in another clinical trial. In addition, patients having diseases that were likely to cause death or significant morbidity during the study period such as carcinoma and immune, infectious or degenerative diseases influencing cognitive functions were excluded. At hospital admission just before PM implantation, patients were asked to fill out various HRQoL questionnaires, that is, the general SF-36 and EQ05D questionnaires, ${ }^{22,23}$ and the disease specific AquaRel questionnaire. ${ }^{24}$ The protocol for this study was approved by the Ethical Commission of the University Medical Center (UMC), Utrecht, The Netherlands. The FOLLOWPACE study adhered to the tenets described in the Declaration of Helsinki.

\section{Health-Related Quality of Life}

The HRQoL of this cohort and in all other comparison groups was measured by the SF-36. The Medical Outcomes Study Short-Form Health Survey ${ }^{6,23,25-27}$ (SF-36) is the most widely used generic questionnaire because of its psychometric characteristics and ability to compare HRQoL across different patient categories. This questionnaire consists of 36 questions, which can be com- prised of eight subscales that measure: (1) physical functioning (PF); (2) role limitations due to physical problems (RP); (3) social functioning (SF); (4) role limitation due to emotional problems (RE); (5) mental health (MH); (6) bodily pain (BP); (7) sense of vitality (EV), and (8) general health (GH). Furthermore, the SF-36 can further be comprised into two overall scores: a physical component scale (PCS) and a mental component subscale (MCS). ${ }^{27}$ Scores of each (sub)scale are normalized to a scale ranging from 0 to 100 , with a lower score representing a lower HRQoL.

\section{Comparison Groups}

We compared the HRQoL of our patients awaiting PM implantation with an (as much as possible age-matched) sample from the general Dutch population and various other patient samples. Data on the HRQoL (measured with the SF-36 questionnaire) of a sample of the general Dutch population, were obtained from a previous study by VanderZee. ${ }^{28}$ In addition, we selected papers from multicenter studies published after 1992 and with more than 100 included patients, with full data on SF-36 scores. We selected seven different patient cohorts: patients with hypertrophic cardiomyopathy, ${ }^{29}$ diabetes, ${ }^{30}$ rheumatoid arthritis (RA), ${ }^{31}$ chronic angina pectoris (cAP), ${ }^{32}$ migraine, ${ }^{33}$ epilepsy, ${ }^{30}$ and patients included in a cardiac rehabilitation program ${ }^{34}$ before any intervention was performed.

\section{Data Analysis}

For our patients in the FOLLOWPACE study, we first established whether the values of SF-36 scores were normally distributed using visual inspection to detect skewness of the data and the Shapiro-Wilk $W$-test, which tests the hypothesis that there is a correlation between the observed values and the normal scores. When the hypothesis is rejected, the distribution is considered as being normal. We assumed a normal distribution for the HRQoL data in the comparison groups where only means and standard deviation were provided. Next we computed the mean differences for all SF-36 subscales between our cohort of PM patients and the general population, and patients with other diseases. Statistical significance of these mean differences was tested using the Student's $t$-test.

Several studies have been published on the interpretation and clinical relevance of statistically significant differences in mean scores of SF-36 subscales. ${ }^{7,35-39}$ To appreciate mean differences of SF-36 data, Cohen introduced the measurement and interpretation of the so-called effect size for HRQoL. An effect size can be computed by dividing the mean difference of the score in each SF-36 subscale between a patient group and a control 
group by the standard deviation of the mean of the control group. An effect size of $<0.20$ can be considered as clinically irrelevant, $0.20-0.49$ as small, $0.50-0.79$ as moderate, and an effect size of $>0.80$ as large and highly relevant. ${ }^{40}$

Finally, a multivariable linear regression analysis was performed on both the overall PCS and MCS scores of the SF-36 to determine whether the patient's gender, age, Body Mass Index (BMI), cardiac history, and pacing indication were independently related to the HRQoL. All analyses were performed using S-Plus Version 6.2.1 (Insightful Corp., Seattle, WA, USA).

\section{Results}

The baseline characteristics of our $818 \mathrm{PM}$ patients are given in Table I. Age distribution and indications for pacing were concordant with that in the rest of Europe, ${ }^{41}$ with a mean age of 73.2 $( \pm 10.5)$ years and atrioventricular conduction disturbances as the most frequent primary indication for PM implantation.

Patients awaiting PM implantation had a significantly lower HRQoL than the general population with a comparable age distribution $(\mathrm{P}<$ 0.001), for all SF-36 scales except for the subscales "BP" $(\mathrm{P}=0.16)$ and "GH" $(\mathrm{P}=0.17)$. (Table II)

Table I.

Baseline Characteristics of 818 Patients Awaiting First PM Implantation

\begin{tabular}{lc}
\hline Patient Characteristics & \\
Male & 60.6 \\
Age in years (range 22-99) & $73.2(10.5)$ \\
Age categories & \\
$22-60(\mathrm{n}=103)$ & 12.6 \\
$61-70(\mathrm{n}=171)$ & 20.9 \\
$71-80(\mathrm{n}=347)$ & 42.4 \\
$\quad 81-100(\mathrm{n}=197)$ & 24.1 \\
Cardiac history (Prior AMl and/or PTCA/ & 67.5 \\
$\quad$ CABG, heart failure, other $\left.{ }^{\star}\right)$ & \\
Main indication for implantation & \\
$\quad$ Atrioventricular conduction & \\
$\quad$ disturbances $(\mathrm{n}=340)$ & 41.5 \\
$\quad$ Sick sinus syndrome, & \\
$\quad$ bradytachycardias $(\mathrm{n}=278)$ & 34.0 \\
$\quad$ Atrial fibrillation with slow ventricular & \\
$\quad$ response $(\mathrm{n}=141)$ & 17.2 \\
$\quad$ Heart failure $(\mathrm{n}=22)$ & \\
$\quad$ Other $(\mathrm{n}=37)$ & 2.7 \\
\hline
\end{tabular}

Numbers are percentages unless stated otherwise.

Abbreviations: $\mathrm{AMI}=$ acute myocardial infarction; $\mathrm{PTCA}=$ percutaneous transluminal coronary angioplasty; $\mathrm{CABG}=$ coronary arterial bypass graft.

*Peripheral vascular disease, His ablations.
The largest difference regarded the subscale "RP" where the observed difference was 38.3 (95\% CI: 30.4-46.1) with an effect size of 0.96. The differences in the two overall scores (PCS: $38.8 \pm 27.1$ vs $43.7 \pm 28.5$ and MCS $46.8 \pm 27.0$ vs $53.2 \pm 24.1$ ) were somewhat smaller with P-values of 0.08 and 0.02 , and effect sizes of 0.18 and 0.24 , respectively (Table II).

The PM population was older (mean $73.2 \pm$ 10.5 years) than the patients in the cardiac rehabilitation study $(59.7 \pm 11.0$ years), and the patients with hypertrophic cardiomyopathy $(43.2 \pm$ 14.7 years). The values of all SF-36 scales in these cohorts were similar, except for the latter patient group on the subscale "RP" (Table III). Patients with cAP were younger than the PM patients $(67.0 \pm 10.0$ years vs $73.2 \pm 10.5$ years), but scored higher on the subscales "PF" and "RP" (effect sizes of 0.86 and 0.59 , respectively) and lower on the "MH" subscale (effect size 0.50). Patients with diabetes scored a higher HRQoL score for the scales "PF," "SF," and "RP," (effect sizes: 0.77, 0.55, and 0.61). Patients with migraine scored higher on the subscales "PF," "RP," "RE," and "GH" (effect sizes of $1.32 ; 0.63 ; 0.62$, and 0.76 ) and lower on "BP" (effect size 0.80). Patients with RA scored similar to patients awaiting PM implantation on most SF36 subscales but lower on "EV" and "BP" (effect sizes 0.56 and 1.26). Patients with epilepsy scored higher on "PF," "RP," and "GH" (effect sizes 0.95, 0.73 , and 0.59 ).

Multivariable linear regression modeling identified patients' gender, presence of heart failure, and diabetes, higher age, and Body Mass Index as independently associated with lower scores on the overall PCS score (Table IV). Gender and age were independently associated with the overall MCS score, where MCS was lower in female and younger patients.

\section{Discussion}

To appreciate our findings, several aspects of the study need consideration. First, when comparing HRQoL between a general population and different patient populations, a non-disease-specific HRQoL questionnaire should be used. The disadvantage of such a questionnaire, however, is the lack of sufficient specificity to detect diseasespecific impairment of health perception in the comparison between different patient groups, potentially undermining the comparability. To reduce this potential we carefully selected data on several patient cohorts that were published not too long ago and obtained from relatively large studies $(N>100)$. Obviously, differences between the patient populations can still exist. Unfortunately, the papers describing these other patient groups did not present sufficient baseline data to allow 
Table II.

Mean Scores (SD) of the SF-36 Subscales of Patients Awaiting First PM Implantation $(n=818)$ in Comparison with an Approximate Age Matched Average Dutch Population (65-75 years, $n=118$ )

\begin{tabular}{|c|c|c|c|c|c|}
\hline & $\begin{array}{l}\text { Patients Awaiting } \\
\text { PM Implantation } \\
\quad(\mathrm{n}=\mathbf{8 1 8})\end{array}$ & $\begin{array}{l}\text { Average controls } \\
\text { (65-75 years) } \\
(\mathrm{n}=118)\end{array}$ & $\begin{array}{c}\text { Difference } \\
(95 \% \mathrm{Cl})\end{array}$ & Effect size* & P-Value \\
\hline Physical functioning & $53.6(28.7)$ & $66.7(26.0)$ & $13.2(8.0-18.3)$ & 0.49 & $<0.001$ \\
\hline Social functioning & $66.0(27.9)$ & $83.2(23.7)$ & $17.2(11.9-22.5)$ & $0.62^{\dagger}$ & $<0.001$ \\
\hline Role limitation (physical) & $30.8(40.0)$ & $69.1(42.5)$ & $38.3(30.4-46.1)$ & $0.96^{\ddagger}$ & $<0.001$ \\
\hline Role limitation (emotional) & $53.8(44.8)$ & $82.9(33.8)$ & $29.1(20.6-37.6)$ & $0.65^{\dagger}$ & $<0.001$ \\
\hline Mental health & $69.0(20.1)$ & $75.9(17.3)$ & $6.9(3.1-10.8)$ & 0.34 & $<0.001$ \\
\hline Energy vitality & $50.9(22.1)$ & $64.2(22.0)$ & $13.3(9.0-17.6)$ & $0.60^{\dagger}$ & $<0.001$ \\
\hline Pain & $71.1(26.6)$ & $74.8(28.0)$ & $3.7(-1.5-9.0)$ & 0.14 & 0.16 \\
\hline General health perception & $56.9(20.1)$ & $60.1(23.9)$ & $3.2(-0.8-7.2)$ & 0.16 & 0.17 \\
\hline Physical component scale & $38.8(27.1)$ & $43.7(28.5)$ & $4.9(-0.4-10.2)$ & 0.18 & 0.08 \\
\hline Mental component scale & $46.8(27.0)$ & $53.2(24.1)$ & $6.4(1.2-11.6)$ & 0.24 & 0.02 \\
\hline
\end{tabular}

*Cohen's effect sizes, defined as mean difference divided by the SD of the control group; $(0.00-0.19)=$ No effect; $(0.20-0.49)=$ Small effect; $(0.50-0.79)^{\dagger}=$ Moderate effect; $(>0.79)^{\ddagger}=$ Large effect.

appropriate adjustment for gender or other sociodemographic variables. Age matching could only be done for the comparison with the general population. The differences measured between our cohort and age-matched populations in the age groups 45-55 years, 55-65 years, and 65-75 years were all concordant with the differences between our total patient cohort and the comparison group at an approximate level. As the sample sizes of the age-matched population groups were fairly small, age-stratified data are not shown. Our patients had a wide age range (22-99 years) though a mean of 73.2 with standard deviation of 10.5 years. Hence, we compared the HRQoL from our PM patients with the general Dutch population with age range of 65 to 75 years.

Second, the HRQoL scores in the studies with patients with epilepsy and diabetes were adjusted for socioeconomic characteristics and comorbidity, which may have led to generally higher SF-36 scores compared to our PM population. Unfortunately, no none-adjusted data were available for these two patient groups. Also, the overall PCS and MCS were missing from almost all papers describing the other patient populations. Hence, we could only compare the difference in HRQoL on the different subscales.

Third, to improve the clinical relevance of the comparisons between our PM patients and various reference or other patient samples, we used the Cohen's effect size. ${ }^{40}$ Although frequently used, this measure is dependent on the reference sample and requires some cut-off values to enhance interpretation.
Fourth, the HRQoL does not depend so much on having a particular disease, but rather on various patient characteristics, such as age, gender, comorbidities (as also reflected in the present study), and the length of the time patients suffer from the disease. From our PM population we only had cardiovascular comorbidity data, which was present in $67.5 \%$ (Table I). This may have resulted in an underestimation of differences between our study cohort and comparison patient groups with cardiac comorbidities. However, for most comparison groups information on comorbidities was not provided. Unfortunately for our PM population, the time period between the diagnosis of the cardiac rhythm disorder and the PM implantation was unknown and could therefore not be analyzed on its association with HRQoL. Furthermore, the multiple comparisons between our PM patients and the other patient groups may have produced some spuriously significant findings. To further avoid spurious significant findings, predictors of the HRQOL were only analyzed for the PCS and MCS and not for all subscales as these overall scores are a direct derivate of the subscales and closely correlated to these subscales.

Finally, to address our concerns whether the HRQoL in a general population in The Netherlands is similar to that in other Western countries ${ }^{42}$ and to study whether the HRQoL in our studied cohort of patients awaiting their first PM implantation was more or less similar to that in earlier published results on HRQoL of patients awaiting PM implantation, ${ }^{43-45}$ we analyzed mean differences between these groups. No major discrepancies were found 


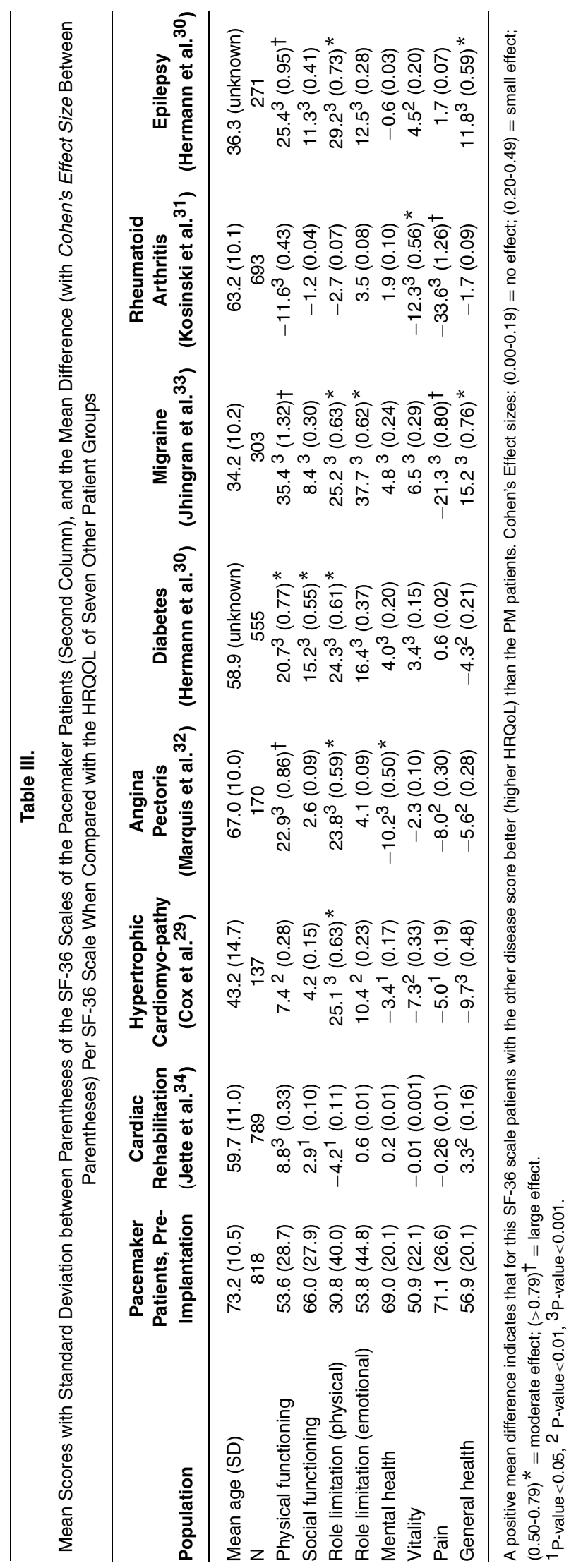

Table IV.

Factors Independently Associated (Based on Multivariable Linear Regression Analysis) with the Overall Physical (38.8 \pm 27.1) and Mental (46.8 \pm 27.0$)$ Component SF-36 Scale in 818 Patients Awaiting First PM Implantation

\begin{tabular}{ccr}
\hline & B (95\% Cl) & P-Value \\
\hline Physical component & & \\
subscale (PCS) & & \\
$\quad$ Female gender & $-1.97(-3.41 ;-0.53)$ & 0.007 \\
Age (in years) & $-0.27(-0.33 ;-0.20)^{*}$ & $<0.001$ \\
BMI (per unit) & $-0.28(-0.48 ;-0.08)^{*}$ & 0.006 \\
$\quad$ Presence heart failure & $-3.20(-5.53 ;-0.87)$ & 0.007 \\
$\quad$ Presence of diabetes & $-2.22(-4.21 ;-0.24)$ & 0.028 \\
$R^{2}=0.11$ & & \\
Mental component & & \\
subscale (MCS) & & \\
$\quad$ Female gender & $-5.80(-7.60 ;-4.00)$ & $<0.001$ \\
$\quad$ Age (in years) & $0.14(0.05 ; 0.22)^{*}$ & 0.001 \\
$R^{2}=0.06$ & & \\
\hline
\end{tabular}

$\mathrm{B}$ and $95 \%$ confidence intervals on patient-related factors with influence on HRQoL SF-36 physical and emotional component subscales.

Abbreviation: $\mathrm{BMI}=$ body mass index.

*Per unit increase.

(results not shown). This strengthens the general applicability of the findings of our study.

\section{Previous Studies}

In comparison to the published data on HRQoL in patients awaiting PM implantation, our results deviate with that of Lopez et al. (PASE study) ${ }^{18}$ and Fleishman et al. (MOST study), ${ }^{14}$ as male patients in our cohort score generally higher on their HRQoL. Furthermore, our findings contradict with the MOST study as the HRQoL is related to the patients' comorbidity such as heart failure and diabetes. However, we confirm the results of Newman et al. (CTOPP study) ${ }^{19}$ that patients at lower age tend to score higher on the physical component subscale than patients over 75 years. ${ }^{14,19}$ In an unselected population of patients awaiting PM implantation both patients at younger age and of male gender tend to score higher on the MCS.

\section{Conclusion}

The HRQoL measured with the SF-36 questionnaire of an unselected patient population just before first PM implantation is significantly lower than that of a general population. The scales "physical functioning," "role limitation due to physical functioning," "social functioning," and "role limitations due to emotional problems" in patients awaiting a PM implantation are scored similar to that in patients joining a cardiac rehabilitation 


\section{QUALITY OF LIFE IN PACEMAKER PATIENTS}

program and to patients with rheumatoid arthritis whereas these scores are lower compared to patients with chronic angina pectoris. Several characteristics such as patients' gender, age, and the presence of cardiovascular comorbidities can support the identification of the patient with outspoken reduced quality of life before PM implantation. Awareness of these physical and emotional aspects of waiting pacemaker recipients should be translated into minimizing the time period between the diagnosis of the cardiac rhythm disorder requiring PM implantation and the implantation procedure itself, and physician's compassion with the individual patient need in terms of support and information.

\section{References}

1. Guyatt GH, Feeny DH, Patrick DL. Measuring health-related quality of life. Ann Intern Med 1993; 118:622-629.

2. McDowell I, Newell C. Measuring health: A guide to rating scales and questionnaires. 2nd Ed. New York, Oxford University Press, 1996.

3. Patrick DL, Bergner M. Measurement of health status in the 1990s. Annu Rev Public Health 1990; 11:165-183.

4. Staquet MJ, Hays RD, Fayers PM. Quality of life assessment in clinical trials. 1st Ed. New York, Oxford University Press, 1998.

5. Stewart AL. Conceptual and methodologic issues in defining quality of life: State of the art. Prog Cardiovasc Nursing 1992; 7:3-11.

6. Ware JE. The assessment of health status. In: Aiken LH, Mechanic D (eds.). Application of Social Sciences to Clinical Medicine and Health Policy. New Brunswick, NJ, Rutgers University Press, 1986, 204-228.

7. Frost MH, Bonomi AE, Estwing Ferrans C, Wong GW, Hays RD. Patient, clinician and population perspectives on determining the clinical significance of quality of life scores. Mayo Clin Proc 2002; 77:488-494.

8. Smith KW, Avis NE, Assmann SF. Distinguishing between quality of life and health status in quality of life research: A meta-analysis. Qual Life Res 1999; 8:447-459.

9. Stewart AL, Ware JE. Measuring function and well-being: The Medical Outcomes Study Approach. Durham, NC, Duke University Press, 1992.

10. Testa MA. Interpretation of quality of life outcomes: Issues that affect magnitude and meaning. Med Care 2000; 38:II-166-II-174.

11. Ware JE. Measuring patients' views: The optimum outcome measure. Br Med J 1989; 306:1429-1430.

12. Bubien RS, Kay GN. A randomized comparison of quality of life and exercise capacity with DDD and VVIR pacing modes. PACE 1990; 13:524.

13. Bubien RS, Knotts-Dolson SM, Plimp VJ, Kay GN. Effect of radiofrequency catheter ablation on health related quality of life and activities of daily living in patients with recurrent arrhythmia. Circulation 1996; 94:1585-1591.

14. Fleischman KE, Orav EJ, Lamas GA, Mangione CM, Schron E, Lee KL, Goldman L. Pacemaker implantation and quality of life in the Mode Selection Trial. Heart Rhythm 2006; 3:653659.

15. Lamas GA, Orav EJ, Stambler BS, Ellenbogen KA, Sgarbossa EB, Huang SKS, Marinchak RA, et al. Quality of life and clinical outcomes in elderly patients treated with ventricular pacing as compared with dual-chamber pacing. N Engl J Med 1998; 338:10971104.

16. Levy T, Walker S, Mason M, Spurrell P, Rex S, Brant S, Paul V. Importance of rate control or rate regulation for improving exercise capacity and quality of life in patients with permanent atrial fibrillation and normal left ventricular function: A randomized controlled study. Heart 2001; 85:171-178.

17. Linde-Edelstam C, Nordlander R, Unden A-L, Orth-Gomer K, Ryden L. Quality of life in patients treated with atrioventricular synchronous pacing compared to rate modulated ventricular pacing: A long term, double-blind, crossover study. Pace Clin Electrophysiol 1992; 15:1467-1476.
Acknowledgments: The authors acknowledge the cooperation of the patients included in this study, cardiologists, and pacemaker technicians of the following hospitals in the Netherlands: Bernhoven Hospital, Veghel; Amphia Hospital, Breda; Reinier de Graaf Gasthuis, Delft; Diaconessen Hospital, Meppel; Medical Center Alkmaar, Alkmaar; Hospital group Twente, Hengelo; VieCuri Medical Center, Venlo; Zaans Medical Center, Zaandam; St. Antonius Hospital, Nieuwegein; Alysis Rijnstate Hospital, Arnhem; Vlietland Hospital, Schiedam; Deventer Hospital, Deventer; VU Medical Center, Amsterdam; Twenteborg Hospital, Almelo; Spaarne Hospital, Heemstede; Westfries Hospital, Hoorn; Atrium Medical Center, Heerlen; Rijnland Hospital, Leiderdorp; University Medical Center, Groningen; Maxima Medical Center, Veldhoven; Antonius Hospital, Sneek; Hospital De Tjongerschans, Heerenveen; Canisius Wilhelmina Hospital, Nijmegen; Diaconessen Hospital, Leiden.

18. Lopez-Jimenez F, Goldman L, Orav EJ, Ellenbogen KA, Stambler BS, Marinchak RA, Wilkoff BL, et al. Health values before and after pacemaker implantation. Am Heart J 2002; 144:687692 .

19. Newman D, Lau C, Tang ASL, Irvine J, Paquette M, Woodend K, Dorian $\mathrm{P}$, et al. Effect of pacing mode on health-related quality of life in the Canadian Trial of Physiologic Pacing. Am Heart J 2003; 145:430-437.

20. Gregoratos G, Cheitlin MD, Conill A, Epstein AE, Fellows C, Ferguson TB, Freedman RA, et al. ACC/AHA guidelines for implantation of cardiac pacemaker and antiarrhythmia devices. A report of the American College of Cardiology/American Heart Association task force on practice guidelines (Committee on pacemaker implantation). JACC 1998; 31:1175-1209.

21. van Eck JWM, van Hemel NM, Grobbee DE, Buskens E, Moons KGM. FOLLOWPACE study: A prospective study on the cost-effectiveness of routine follow-up visits in patients with a pacemaker. Europace 2006; 8:60-64.

22. Brooks R. EuroQol: The current state of play. Health Policy 1996; 37:53-72.

23. Ware JE, Snow KK, Kosinski M, Gandek B. SF-36 Health Survey Manual and Interpretation Guide. Boston, The Health Institute, New England Medical Center, 1993.

24. Stofmeel MAM, Post MW, Kelder JC, Grobbee DE, van Hemel NM. Psychometric properties of Aquarel: A disease-specific quality of life questionnaire for pacemaker patients. J Clin Epidemiol 2001; 54:157-165.

25. McHorney CA, Ware JE, Raczek AE. The MOS 36-Item Short-Form Health Survey (SF-36): II. Psychometric and clinical tests of validity in measuring physical and mental health constructs. Med Care 1993; 31:247-263.

26. Ware JE, Sherbourne CD. The RAND-36 Short-Form Health Survey: I. Conceptual framework and item selection. Med Care 1992; 30:473481.

27. Ware JE, Kosinski M, Keller SD. SF-36 Physical and Mental Health Summary Scales: A User's Manual. Boston, The Health Institute, New England Medical Center, 1994.

28. VanderZee KI, Sanderman R, Heyink JW, de Haes H. Psychometric qualities of the RAND 36 item health survey 1.0: A multidimensional measure of general health status. Int J Beh Med 1996; 3:104122.

29. Cox S, O’Donoghue AC, McKenna W, Steptoe A. Health related quality of life and psychological wellbeing in patients with hypertrophic cardiomyopathy. Heart 1997; 78:182-187.

30. Hermann BP, Vickrey B, Hays RD, Cramer J, Devinsky O, Meador $\mathrm{K}$, Perrine K, et al. A comparison of health-related quality of life in patients with epilepsy, diabetes and multiple sclerosis. Epilep Res 1996; 25:113-118.

31. Kosinski M, Zhao SZ, Dedhiya S. Determining minimally important changes in generic and disease-specific health-related quality of life questionnaires in clinical trials of rheumatoid arthritis. Atrhritis Rheum 2000; 43:1478-1487.

32. Marquis P, Fayol C, Joire JE. Clinical validation of a quality of life questionnaire in angina pectoris patients. Eur Heart J 1995; 16:15541560. 


\section{MARTIJN VAN ECK, ET AL.}

33. Jhingran P, Cady RK, Rubino J, Miller D, Grice RB, Gutterman DL. Improvements in health-related quality of life with sumatriptan treatment for migraine. J Fam Pract 1996; 42:36-42.

34. Jette DU, Downing J. Health status of individuals entering a cardiac rehabilitation program as measured by the medical outcomes study 36-item short-form survey (SF-36). Physical Therapy 1994; 74:521527.

35. Cella D, Bullinger M, Scott C, Barofsky I. Group vs individual approaches to understanding the clinical significance of differences or changes in quality of life. Mayo Clin Proc 2002; 77:384392.

36. Guyatt GH, Osoba D, Wu AW, Wyrwich KW, Norman GR. Methods to explain the clinical significance of health status measures. Mayo Clin Proc 2002; 77:371-383.

37. Norman GR, Sloan JA, Wyrwich KW. Interpretation of changes in health-related quality of life. The remarkable universality of half a standard deviation. Med Care 2003; 41:582-592.

38. Symonds T, Berzon R, Marquis P, Rummans TA. The clinical significance of quality of life results: Practical considerations for specific audiences. Mayo Clin Proc 2002; 77:572-583.

39. Wyrwich KW, Tierney WM, Babu AN, Kroenke K, Wolinsky FD. A comparison of clinically important differences in health-related quality of life for patients with chronic lung diseases, asthma, or heart disease. Health Services Research 2005; 40:577-592.

40. Cohen J. Statistical Power Analysis for the Behavioral Sciences. Hilsdale, Lawrence Erlbaum Associates, 1988.

41. Ector H, Rickards AF, Kappenberger L, Linde C, Vardas P, Oto A Santini M, et al. The world survey of cardiac pacing and implantable cardioverter defibrillators: Calendar year 1997-Europe. Pacing Clin Electrophysiol 2001; 24:863-868.

42. Hopman WM, Towheed T, Anastassiades T, Tenenhouse A, Poliquin S, Berger C, Joseph L, et al. Canadian normative data for the SF-36 health survey. CMAJ 2000; 163:265-271.

43. Carlson MD, Ip J, Messenger J, Beau S, Kalbfleisch S, Gervais P, Cameron DA, et al. A new pacemaker algorithm for the treatment of atrial fibrillation. JACC 2003; 42:627-633.

44. Hohnloser SH, Kuck K-H, Lilienthal J. Rhythm or rate control in atrial fibrillation-Pharmacological intervention in atrial fibrillation (PIAF): A randomised trial. Lancet 2000; 356:1789-1794.

45. Link MS, Hellkamp AS, Estes III NAM, Orav EJ, Ellenbogen KA, Ibrahim B, Greenspon A, et al. High incidence of pacemake syndrome in patients with sinus node dysfunction treated with ventricular-based pacing in the Mode Selection Trial (MOST). J Am Coll Cardiol 2004; 43:2066-2071. 